\title{
Exercise-induced pulmonary hypertension: at last!
}

\author{
Robert Naeije ${ }^{1}$, Anton Vonk Noordegraaf ${ }^{2}$ and Gabor Kovacs ${ }^{3}$ \\ Affiliations: ${ }^{1}$ Erasme University Hospital, Brussels, Belgium. ${ }^{2}$ Vrije Universiteit Medical Center, Amsterdam,
} The Netherlands. ${ }^{3}$ Medical University of Graz, Graz, Austria.

Correspondence: R. Naeije, Dept of Pathophysiology, Erasme Campus, 808 Lennik Road, B-1070 Brussels, Belgium. E-mail: rnaeijedulb.ac.be

$@$ ERSpublications

Two studies in the September issue of the ERJ support the recognition of exercise-induced pulmonary hypertension http://ow.ly/Pk7xn

Stress tests are for the identification of silent pathology. Applications to medical diagnosis are numerous. For example, ventilation $\left(V^{\prime} \mathrm{E}\right)$ and mean pulmonary artery pressure (mPAP) may overlap at rest, but markedly diverge during exercise in patients with pulmonary hypertension or heart failure and in healthy controls (figure 1). Accordingly, measurements of mPAP during exercise have been part of the diagnostic work-up of pulmonary hypertension since the early years of cardiac catheterisation, more than half a century ago [1]. Yet "exercise-induced pulmonary hypertension", defined by higher than normal mPAP during exercise has failed to gain acceptance [2]. Why is this?

A problem has been in the definition of upper limits of normal and agreement on cut-off for pathological values. Early on, the upper limit of normal of resting mPAP was established at $20 \mathrm{mmHg}$ [1], but the definition of an upper limit of normal of exercise mPAP took longer. FisHMAN [3] thought that mPAP during exercise would not normally exceed $25 \mathrm{mmHg}$ in healthy subjects. He was aware of higher values previously reported in athletic individuals $[4,5]$ but assumed that this was related to high cardiac outputs irrelevant to dyspnoeic patients. Therefore, in his time, it was generally agreed upon that pulmonary hypertension could be defined by a mPAP higher than $25 \mathrm{mmHg}$ at rest and $30 \mathrm{mmHg}$ at exercise. It is worth noting that a safety margin of $5 \mathrm{mmHg}$ above the upper limits of normal was applied to limit the risk of false-positive diagnosis. These were the entry criteria in the National Institute of Health registry for pulmonary arterial hypertension, then called "primary" pulmonary hypertension [6].

In the meantime, invasive measurements of the pulmonary circulation in healthy subjects accumulated, up to a total of 1187 at exercise reviewed in 2008 [7]. An analysis of these data not surprisingly confirmed $20 \mathrm{mmHg}$ as upper limit of normal of resting mPAP, but disclosed an under-recognised variability of protocols and responses to exercise, with mPAP often measured higher than $30 \mathrm{mmHg}$, especially in older subjects [7]. It was therefore decided at the 4th World Symposium of Pulmonary Hypertension in Dana Point, in 2008 to withdraw exercise criteria from the diagnosis of pulmonary hypertension [8]. This position was reiterated at the 5th World Symposium of Pulmonary Hypertension held in Nice in 2013 [2].

Defining an upper limit of normal of mPAP at exercise is difficult as this variable depends on cardiac output (CO), wedge pressure and pulmonary vascular resistance (PVR), all of which are affected by workload. However, in conditions of purely dynamic exercise, flow is predominant and thus the response can be standardised by a linear adjustment of a multipoint mPAP-CO relationship. It has been recently established that the slope of mPAP-CO relationships may vary from almost flat to a five- to six-fold increase, but does not exceed $3 \mathrm{mmHg} \cdot \mathrm{min} \cdot \mathrm{L}^{-1}$ in normal individuals [9]. This corresponds to a peak exercise total PVR (TPVR, i.e. mPAP/CO) of 3 Wood units (WU) [9]. However, a mPAP-CO relationship $>3 \mathrm{mmHg}$ is not diagnosis-specific. Further steps are needed to identify causal pulmonary vascular disease,

Received: April 172015 | Accepted: April 202015

Conflict of interest: None declared.

Copyright @ERS 2015 

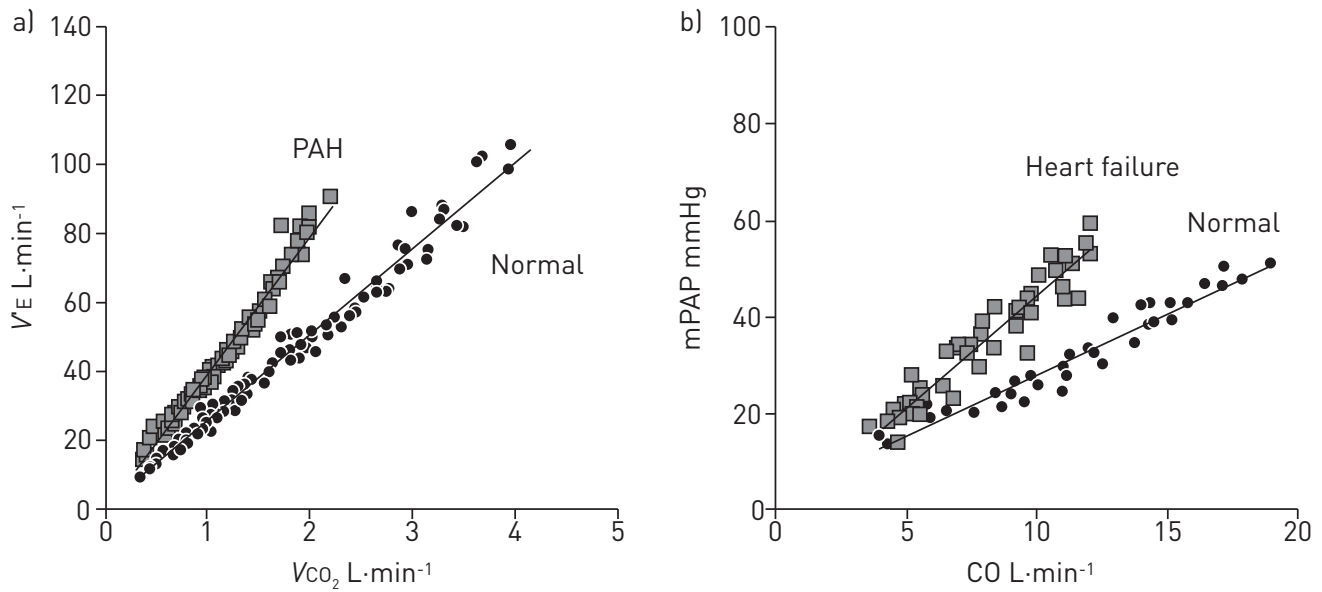

FIGURE 1 a) Adjusted measurements of ventilation $\left(V^{\prime} E\right)$ as a function of carbon dioxide output $\left(V \mathrm{CO}_{2}\right)$ in 10 patients with pulmonary arterial hypertension (PAH), and b) mean pulmonary artery pressure (mPAP) as a function of cardiac output (CO) in six patients with heart failure versus matched controls. Measurements overlap at rest, but diverge during exercise. Courtesy of V. Faoro, M. Vicenzi and G. Deboeck.

diastolic heart failure, or both [10]. In the meantime, exercise-induced pulmonary hypertension, however measured, has been shown to be of diagnostic and/or prognostic relevance in mitral valve disease [11], aortic stenosis [12], heart failure [13], systemic sclerosis [14-16], chronic obstructive pulmonary disease [17] and symptomatic patients after pulmonary endarterectomy [18].

Further support to the notion of exercise-induced pulmonary hypertension is provided by two studies in the present issue of the European Respiratory Journal. In the first, HeRvé et al. [19] report on haemodynamics in 169 consecutive subjects with normal resting mPAP $\leqslant 20 \mathrm{mmHg}$. The subjects were classified into controls without heart or lung disease $(n=68)$ versus patients with pulmonary vascular disease $(n=49)$ and left heart disease $(n=52)$. TPVR and mPAP at maximal exercise was accurate with receiver operating characteristic area under the curve of 0.99 and 0.95 , respectively, for discriminating controls versus patients with pulmonary vascular disease or left heart disease. The old criterion of mPAP $>30 \mathrm{mmHg}$ had a sensitivity of 0.98 but a specificity of 0.77 . Combining maximum $\mathrm{mPAP}>30 \mathrm{mmHg}$ and TPVR $>3 \mathrm{WU}$ retained sensitivity at 0.93 but improved specificity to 1.0. The accuracy of the combined criteria was high across different age groups, sex, body mass index and diagnosis.

It is interesting that the "old" definition of exercise-induced pulmonary hypertension was not that bad after all, but could be improved by a correction for the flow, which any physiologist would happily approve. Conversely, a cut-off value of an exercise TPVR of $3 \mathrm{WU}$ is perhaps too tight, especially since the study by Hervé et al. [19] included only a small number of healthy subjects aged more than 70 years. Furthermore, as is the case for resting measurements, some safety margin may be needed. This will have to be evaluated prospectively in future studies on different patient populations.

In the second study, DEGANI-Costa et al. [20] report on exercise haemodynamics in 27 patients with interstitial lung disease (ILD) and normal or near-normal mPAP at rest and in 11 matched controls. All control subjects had a $\mathrm{mPAP}-\mathrm{CO}$ slope $<3 \mathrm{mmHg} \cdot \mathrm{min} \cdot \mathrm{L}^{-1}$ which confirms, once again, current views on the limits of normal of the pulmonary circulation $[9,10] .15$ ILD patients had a mPAP-CO slope $\geqslant 3 \mathrm{mmHg} \cdot \mathrm{min} \cdot \mathrm{L}^{-1}$. They did not differ from the ILD patients with no exercise-induced pulmonary hypertension in terms of age, sex, body mass index pulmonary function testing or degree of exercise oxygen desaturation, but had a decreased peak oxygen uptake $\left(\mathrm{OO}_{2}\right)$ and an increased $V^{\prime} \mathrm{E}$.

These results confirm previous reports that a steep mPAP-CO relationship, starting at the upper limit of normal, is associated with a decreased exercise capacity [15, 18, 20-23]. This is presumably related to an afterload limitation of right ventricular flow output, but may require confirmation with exercise measurements of function, cardiac output and oxygen extraction.

Altogether, these results reinforce the notion that a diagnosis of exercise-induced pulmonary hypertension can be made and is relevant. There is sufficient evidence to define exercise-induced pulmonary hypertension by an exercise-induced increase in $\mathrm{mPAP}$ to $>30 \mathrm{mmHg}$ at a cardiac output $<10 \mathrm{~L} \cdot \mathrm{min}^{-1}$, or a TPVR $>3$ WU. Some experts might wish to lift the bar by a few $\mathrm{mmHg}$ to clearly differentiate upper limit of normal from pathologic. Causes of exercise-induced pulmonary hypertension are heart failure 
and/or latent pulmonary vascular disease. Exercise-induced pulmonary hypertension is associated with decreased exercise capacity and poor prognosis.

Yet questions remain. Measurements during exercise are hampered by respiratory pressure swings, especially in patients with obstructive lung diseases, which require a high level of expertise in the reading of pulmonary vascular pressure tracings $[24,25]$. Another often overlooked problem is the zero levelling in various positions, from supine to upright during exercise, which need careful three-dimensional adjustment [25]. Since exercise-induced pulmonary hypertension occurs in those with latent or early disease, there is a preference for the use of imaging over invasive measurements. In highly trained environments this is feasible with excellent accuracy, but an inherent lack of precision requires repeated checks, internal controls and eventual invasive confirmation [26]. As exercise stresses the pulmonary circulation through an increase in $\mathrm{CO}$, there is current consideration of alternative dobutamine testing [27]. Attention is now also turning to the right ventricle, with evaluation of "contractile reserve" as an estimation of the adequacy of the coupling of right ventricular function to the pulmonary circulation [28, 29]. This has been recently shown with invasive measurements to be of major importance in patients with severe pulmonary hypertension [30]. The combination of noninvasive evaluation of right ventricular -arterial coupling and cardiopulmonary exercise testing with measurements of peak $V_{\mathrm{O}_{2}}$ and $V^{\prime} \mathrm{E} / V_{\mathrm{CO}}$ slopes has already been shown to be of diagnostic and prognostic relevance in heart failure [31].

After a more than half a century of scepticism, exercise-induced pulmonary hypertension is finally coming out. P. Hervé, L.H. Degani-Costa and their colleagues are to be commended for their important contributions to a robust definition of this entity and understanding of its clinical relevance. Agreement on terminology and methods are essential for the integration of exercise-induced pulmonary hypertension into diagnosis and risk assessment in patients with pulmonary hypertension.

\section{References}

1 Wood P. Pulmonary hypertension with special reference to the vasoconstrictive factor. Br Heart J 1958; 20: 557-570.

2 Hoeper MM, Bogaard HJ, Condliffe R, et al. Definitions and diagnosis of pulmonary hypertension. J Am Coll Cardiol 2013; 62: D42-D50.

3 Fishman AP. Pulmonary circulation. In: Handbook of Physiology, Section 3: The Respiratory System, Volume 1: Circulation and Nonrespiratory Functions. Edited by the American Physiological Society. Bethesda, American Physiological Society, 1985; pp. 93-165.

4 Bevegaard S, Holmgren A, Jonsson B. The effect of body position on the circulation at rest and during exercise, with special reference to the influence of stroke volume. Acta Physiol Scand 1960; 49: 279-298.

5 Granath A, Jonsson B, Strandell T. Circulation in healthy old men, studied by right heart catheterization at rest and during exercise in supine and sitting position. Acta Med Scand 1964; 176: 425-446.

6 Rich S, Dantzker DR, Ayres SM, et al. Primary pulmonary hypertension: a national prospective study. Ann Intern Med 1987; 107: 216-223.

7 Kovacs G, Berghold A, Scheidl S, et al. Pulmonary arterial pressure during rest and exercise in healthy subjects: a systematic review. Eur Respir J 2009; 34: 888-894.

8 Badesch DB, Champion HC, Sanchez MA, et al. Diagnosis and assessment of pulmonary arterial hypertension. J Am Call Cardiol 2009; 54: S55-S66.

9 Naeije R, Vanderpool R, Dhakal BP, et al. Exercise-induced pulmonary hypertension: physiological basis and methodological concerns. Am J Respir Crit Care Med 2013; 187: 576-583.

10 Lewis GD, Bossone E, Naeije R, et al. Pulmonary vascular hemodynamic response to exercise in cardiopulmonary diseases. Circulation 2013; 128: 1470-1479.

11 Magne J, Lancellotti P, Piérard LA. Exercise pulmonary hypertension in asymptomatic degenerative mitral regurgitation. 2010; 122: 33-41.

12 Lancellotti P, Magne J, Donal E, et al. Determinants and prognostic significance of exercise pulmonary hypertension in asymptomatic severe aortic stenosis. Circulation 2012; 126: 851-859.

13 Lewis GD, Murphy RM, Shah RV, et al. Pulmonary vascular response patterns during exercise in left ventricular systolic dysfunction predict exercise capacity and outcomes. Circ Heart Fail 2011; 4: 276-285.

14 Condliffe R, Kiely DG, Peacock AJ, et al. Connective tissue disease-associated pulmonaryarterial hypertension in the modern treatment era. Am J Respir Crit Care Med 2009; 179: 151-157.

15 Kovacs G, Maier R, Aberer E, et al. Borderline pulmonary arterial pressure is associated with decreased exercise capacity in scleroderma. Am J Respir Crit Care Med 2009; 180: 661-886.

16 Saggar R, Khanna D, Furst DE, et al. Exercise-induced pulmonary hypertension associated with systemic sclerosis: four distinct entities. Arthritis Rheum 2010; 62: 3741-3750.

17 Kessler R, Faller M, Weitzenblum E, et al. "Natural history" of pulmonary hypertension in a series of 131 patients with chronic obstructive lung disease. Am J Respir Crit Care Med 2001; 164: 219-224.

18 Claessen G, La Gerche A, Dymarkowski S, et al. Pulmonary vascular and right ventricular reserve in patients with normalized resting hemodynamics after pulmonary endarterectomy. J Am Heart Assoc 2015; 4: e001602.

19 Herve P, Lau EM, Sitbon O, et al. Criteria for diagnosis of exercise pulmonary hypertension. Eur Respir J 2015; 46: 728-737.

20 Degani-Costa LH, Levarge B, Digumarthy SR, et al. Pulmonary vascular response patterns during exercise in interstitial lung disease. Eur Respir J 2015; 46: 738-749.

21 Tolle JJ, Waxman AB, Van Horn TL, et al. Exercise-induced pulmonary arterial hypertension. Circulation 2008; 118: 2183-2189. 
22 La Gerche A, MacIsaac AL, Burns AT, et al. Pulmonary transit of agitated contrast is associated with enhanced pulmonary vascular reserve and right ventricular function at exercise. J Appl Physiol 2010; 109: 1307-1317.

23 Lalande S, Yerly P, Faoro V, et al. Pulmonary vascular distensibility predicts aerobic capacity in healthy individuals. J. Physiology 2012; 590: 4279-4288.

24 Boerrigter $\mathrm{BG}$, Waxman $\mathrm{AB}$, Westerhof $\mathrm{N}$. Measuring central pulmonary pressures during exercise in COPD: how to cope with respiratory effects. Eur Respir J 2014; 43: 1316-1325.

25 Kovacs G, Avian A, Pienn M, et al. Reading pulmonary vascular pressure tracings. How to handle the problems of zero leveling and respiratory swings. Am J Respir Crit Care Med 2014; 190: 252-257.

26 Naeije R, D'Alto M, Forfia PR. Clinical and research measurement techniques of the pulmonary circulation: the present and the future. Progr Cardiovasc Dis 2015; 57: 463-472.

27 Lau EM, Vanderpool RR, Choudhary P, et al. Dobutamine stress echocardiography for the assessment of pressure-flow relationships of the pulmonary circulation. Chest 2014; 146: 959-956.

28 Sharma T, Lau EM, Choudhary P, et al. Dobutamine stress for evaluation of right ventricular reserve in pulmonary arterial hypertension. Eur Respir J 2015; 45: 700-708.

29 Guihaire J, Haddad F, Noly PE, et al. Right ventricular reserve in a piglet model of chronic pulmonary hypertension. Eur Respir J 2015; 45: 709-717.

30 Spruijt OA, de Man FS, Groepenhoff $\mathrm{H}$, et al. The effects of exercise on right ventricular contractility and right ventricular-arterial coupling in pulmonary hypertension. Am J Respir Crit Care Med 2015; 191: 1050-1057.

31 Guazzi M, Naeije R, Arena R, et al. Echocardiography of right ventriculo-arterial coupling combined with cardiopulmonary exercise testing to predict outcome in heart failure. Chest 2015; 148: 226-234. 